Check for updates

Cite this: RSC Adv., 2019, 9, 2156

Received 7th October 2018

Accepted 18th December 2018

DOI: $10.1039 / \mathrm{c} 8 \mathrm{ra0} 8284 \mathrm{~g}$

rsc.li/rsc-advances

\section{Purification and rapid dissolution of potassium sulfate in aqueous solutions}

\author{
Shoujiang Li, ${ }^{a}$ Kaige Sun, ${ }^{a}$ Yunliang Zhao, (D) *ab Guihua Nie ${ }^{a}$ and Shaoxian Song ${ }^{b}$
}

Water soluble potassium sulfate dissolves rapidly and completely in water. Its main characteristics are purity and dissolution rate. In this study, the purification and rapid dissolution of potassium salt $\left(\mathrm{K}_{2} \mathrm{SO}_{4}\right)$ separated from potassium brine deposits collected from Lop Nur basin of China (referred to as $\mathrm{LN} \mathrm{K}_{2} \mathrm{SO}_{4}$ ) were studied for utilization in agricultural farming as a potash fertilizer. First, the dissolving-crystallizing process was conducted to remove the insoluble content and improve the purity of $\mathrm{K}_{2} \mathrm{SO}_{4}$. Second, physical modification of $\mathrm{K}_{2} \mathrm{SO}_{4}$ surfaces was accomplished based on the Noyes-Whitney equation. The results showed that the water insoluble content could be completely removed and the purity of $\mathrm{K}_{2} \mathrm{SO}_{4}$ reached $100 \%$ in the purification process. The dissolution rate was significantly improved with the help of environmentally-friendly additives such as sodium tripolyphosphate (STPP)/urea phosphate (UP). These additives ameliorated the diffusion coefficient $(D)$ and the diffusion layer thickness $(h)$ for $\mathrm{K}_{2} \mathrm{SO}_{4}$. Results also demonstrated that a larger $\mathrm{K}_{2} \mathrm{SO}_{4}$ surface area $(S)$ induced a higher dissolution rate.

\section{Introduction}

Potassium is one of the three essential elements for plants to maintain proper growth. ${ }^{1-5}$ Potash fertilizers used in agriculture usually contain two types: one is potassium chloride ( $\mathrm{KCl}$ ), which is harmful to some crops, increases soil salinity and $\mathrm{pH}$ of the soil, and the other is potassium sulfate $\left(\mathrm{K}_{2} \mathrm{SO}_{4}\right)$, which is a chlorine-free, high-quality, potent potash fertilizer, especially indispensable for tobacco, tea, potatoes, watermelon, sugar beets and other economic crops that are sensitive to chlorine. ${ }^{6-9}$

Fully water-soluble potassium sulfate can dissolve rapidly and completely in water, allowing it to be more efficiently absorbed and utilized by crops. More importantly, $\mathrm{K}_{2} \mathrm{SO}_{4}$ can be applied in agricultural facilities for processes such as sprinkler irrigation and drip irrigation. Overall, this allows for the integration of water and fertilizer, a reduction in water usage, fertilizer-saving, reduced labor and increased production. ${ }^{\mathbf{1 0 , 1 1}}$ As a result, water-soluble fertilizer is a promising candidate for the simultaneous application of water and fertilizer technology for reduced water consumption in agricultural applications.

Lop Nur salt lake, located in the eastern Tarim basin, contains the biggest potassium brine deposits discovered in China. These deposits also contain a magnesium sulfate subtype brine and can be used to produce potassium sulfate fertilizers. ${ }^{12,13}$ Through the exploitation and utilization of Lop Nur salt lake, SDIC Xinjiang Lop Nur Potash Co. Ltd. (SLNP) has

${ }^{a}$ School of Resources and Environmental Engineering, Wuhan University of Technology, Luoshi Road 122, Wuhan, Hubei, 430070, China.E-mail: zyl286@whut.edu.cn

${ }^{b}$ Hubei Key Laboratory of Mineral Resources Processing and Environment, Wuhan University of Technology, Luoshi Road 122, Wuhan, Hubei, 430070, China become the biggest $\mathrm{K}_{2} \mathrm{SO}_{4}$ production company in the world with a $\mathrm{K}_{2} \mathrm{SO}_{4}$ yield of 1.6 million ton per year. ${ }^{14,15}$ The insoluble content in $\mathrm{K}_{2} \mathrm{SO}_{4}$ production affects not only the purity of $\mathrm{K}_{2} \mathrm{SO}_{4}$, but also the dissolution rate. However, Lop Nur agricultural $\mathrm{K}_{2} \mathrm{SO}_{4}\left(\mathrm{LN}_{2} \mathrm{SO}_{4}\right)$ contains about $1 \mathrm{wt} \%$ insoluble residue, which decreased the purity of $\mathrm{K}_{2} \mathrm{SO}_{4}$ and made it dissolve slowly and incompletely. Moreover, the purity of LN $\mathrm{K}_{2} \mathrm{SO}_{4}$ does not meet the national standard for water soluble fertilizer HG/T4365-2012, where the insoluble content must be less than $0.5 \mathrm{wt} \%$. Therefore, it is necessary to investigate the purification of $\mathrm{LN} \mathrm{K}_{2} \mathrm{SO}_{4}$.

The process for dissolving a solid requires two consecutive stages. In the first stage, solute molecules are released from the solid surface into the solution. In the second stage, dissolved molecules are transferred from the solid-liquid interface to the solution by diffusion or convection. ${ }^{16-18}$ The dissolution process can be explained by the Noyes-Whitney ${ }^{19,20}$ equation: ${ }^{19,20}$

$$
\frac{\mathrm{d} m}{\mathrm{~d} t}=V M \frac{\mathrm{d} C}{\mathrm{~d} t}=\frac{M D S}{h}\left(C_{\mathrm{s}}-C\right)
$$

where $\mathrm{d} m / \mathrm{d} t$ represents the dissolution rate, $S$ is the surface area of the solid particle, $D$ is the diffusion coefficient, $C$ and $C_{\mathrm{s}}$ represent the concentrations of the solute in the solution at a certain time $(t)$ and solubility, respectively, and $M$ and $h$ are the relative molecular mass and diffusion layer thickness of the solute, respectively. This equation means that the dissolution rate can be controlled by regulating parameters like $D, S$ and $h$.

Potassium sulfate dissolution has drawn widespread attention. Kubota stated that traces of foreign ions (trivalent chromium and trivalent iron) have a significant effect on the 
Table 4 Particle size distribution for $\mathrm{LN} \mathrm{K}_{2} \mathrm{SO}_{4}$

\begin{tabular}{lllllllll}
\hline & \multicolumn{1}{l}{ Size fraction $(\mu \mathrm{m})$} & & & \\
\cline { 2 - 6 } $\mathrm{LN} \mathrm{K}_{2} \mathrm{SO}_{4}$ & +450 & $-450+300$ & $-300+150$ & $-150+105$ & $-105+74$ & $-74+45$ & -45 \\
\hline Yield $(\%)$ & 0.33 & 6.73 & 18.64 & 60.49 & 1.26 & 11.2 & 1.35 \\
\hline
\end{tabular}

solid phase was separated from the solution using a qualitative filter paper. The obtained solid was dried at $105{ }^{\circ} \mathrm{C}$ in an oven until a constant weight was recorded. Finally, the purified LN $\mathrm{K}_{2} \mathrm{SO}_{4}$ ( $\mathrm{PLN} \mathrm{K}_{2} \mathrm{SO}_{4}$ ) was obtained. The chemical composition of PLN $\mathrm{K}_{2} \mathrm{SO}_{4}$ was determined using the same method as that for $\mathrm{LN} \mathrm{K}_{2} \mathrm{SO}_{4}$. The crystallization yield was calculated by using the following equation:

$$
y=\frac{m_{1}}{m_{2}} \times 100 \%
$$

where $m_{1}$ and $m_{2}$ represent the mass of the crystallization solid and dosage of $\mathrm{LN} \mathrm{K}_{2} \mathrm{SO}_{4}$.

\subsection{Rapid dissolution of potassium sulfate}

To improve the dissolution rate of $\mathrm{K}_{2} \mathrm{SO}_{4}$, the purified $\mathrm{LN} \mathrm{K}_{2} \mathrm{SO}_{4}$ ( $\mathrm{PLN} \mathrm{K}_{2} \mathrm{SO}_{4}$ ) product was mixed with some additives such as dispersants, wetting agents and surfactants. The procedures were as follows: first, additives with a different mass ratio (accounting for the mass of $\mathrm{PLN} \mathrm{K}_{2} \mathrm{SO}_{4}$ ), and $\mathrm{PLN} \mathrm{K}_{2} \mathrm{SO}_{4}$ were mechanically ground to form a homogeneous mixture. The mixture was then crushed at different times with a high-speed crusher (FW-100, China) to achieve a suitable granular grade. Afterwards, $100 \mathrm{~g}$ of the above mixture was added to $1 \mathrm{~L}$ of water at room temperature under a stirring speed of $150 \mathrm{rpm}$. An electrical conductivity meter (A215, ORION, USA) was used to determine the end of the dissolution process. The conductivity of the solution increased as the dissolution process progressed and then reached equilibrium when the dissolution was completed. Meanwhile, the dissolution time was recorded when the conductivity reached equilibrium. The dissolution rate was expressed in terms of dissolution time.

\section{Results and discussion}

\subsection{Purification of Lop Nur agricultural potassium sulfate}

It can be seen from Table 2 that the water insoluble content in the $\mathrm{LN} \mathrm{K}_{2} \mathrm{SO}_{4}$ samples was $0.76 \mathrm{wt} \%$, which was higher than the national standard of $0.5 \mathrm{wt} \%$. The high insoluble content had a negative effect on the dissolution of $\mathrm{LN} \mathrm{K}_{2} \mathrm{SO}_{4}$. Purification significantly and efficiently solved the problem. After comparing Table 3 with Table 2 , it can be obviously seen that the insoluble content was efficiently removed and that the impurity content for the ions $\left(\mathrm{Mg}^{2+}, \mathrm{Ca}^{2+}, \mathrm{Na}^{+}, \mathrm{Cl}^{-}\right)$decreased after purification. Moreover, the $\mathrm{K}_{2} \mathrm{O}$ content increased to $54.67 \%$ in this experiment. During the purification process, the dissolution temperature, liquid to solid ratio, crystallization temperature and time were very vital for the dissolution and crystallization process. Thus, these four factors were discussed in detail.
3.1.1 Effect of dissolution temperature and liquid to solid ratio. Fig. 1 illustrates the yield for different liquid to solid ratios at temperatures of $100{ }^{\circ} \mathrm{C}, 80{ }^{\circ} \mathrm{C}$ and $60{ }^{\circ} \mathrm{C}$ under crystallization temperature of $30^{\circ} \mathrm{C}$ and crystallization time of $24 \mathrm{~h}$. Based on Fig. 1, it can be found that the yield increased and reached a plateau with the liquid to solid ratio increasing, and then the yield decreased significantly as the liquid to solid ratio continued to increase at the same temperature. The liquid to solid ratios for the three temperatures $\left(100{ }^{\circ} \mathrm{C}, 80{ }^{\circ} \mathrm{C}, 60{ }^{\circ} \mathrm{C}\right)$ were $4: 1,4.5: 1$ and $5.3: 1$, respectively. However, the yield $(25.35 \%)$ was low at $60{ }^{\circ} \mathrm{C}$. Considerately, a high temperature meant high energy consumption and a low temperature represented a low yield. Therefore, the ideal condition was $80^{\circ} \mathrm{C}$ with a corresponding $4.5: 1$ liquid-solid ratio.

3.1.2 Effect of crystallization temperature and time. The effect of cooling crystallization temperature and time are illustrated in Fig. 2(a) and (b), respectively. Clearly, crystallization temperature was significant to the yield, which dropped drastically as the temperature increased. However, it was very costly to implement a low temperature in a room environment. Therefore, temperatures such as $20^{\circ} \mathrm{C}, 25{ }^{\circ} \mathrm{C}$ and $30^{\circ} \mathrm{C}$ were selected to investigate the relationship between crystallization time and yield. It can be seen from Fig. 2(b) that the crystallization yield initially increased with crystallization time and then reached a plateau until $12 \mathrm{~h}$ at each temperature. In addition, the yield was $39.81 \%, 36.28 \%$ and $34.12 \%$ at $20{ }^{\circ} \mathrm{C}$, $25{ }^{\circ} \mathrm{C}$ and $30{ }^{\circ} \mathrm{C}$, respectively.

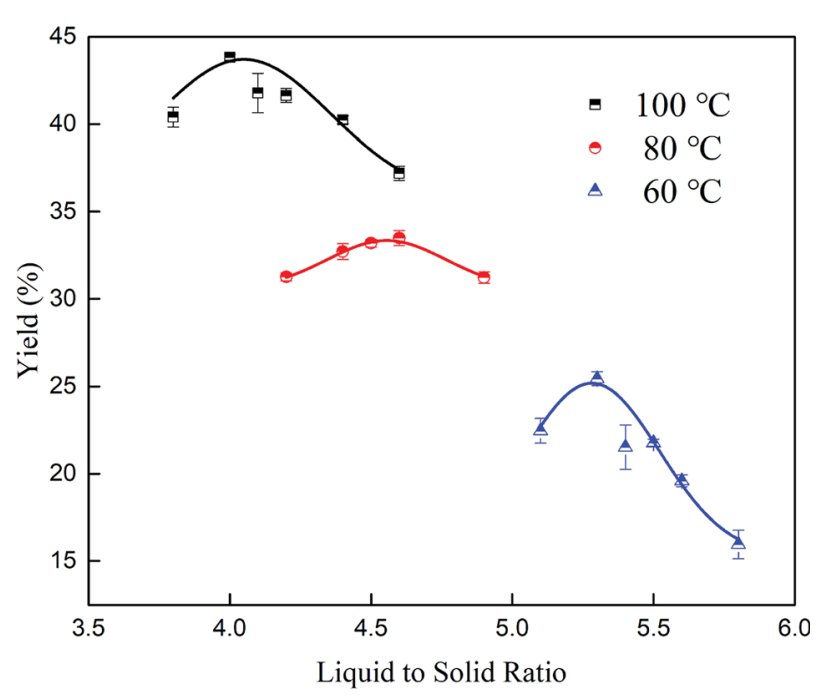

Fig. 1 Effect of the liquid to solid ratio on the yield at different dissolving temperatures. 

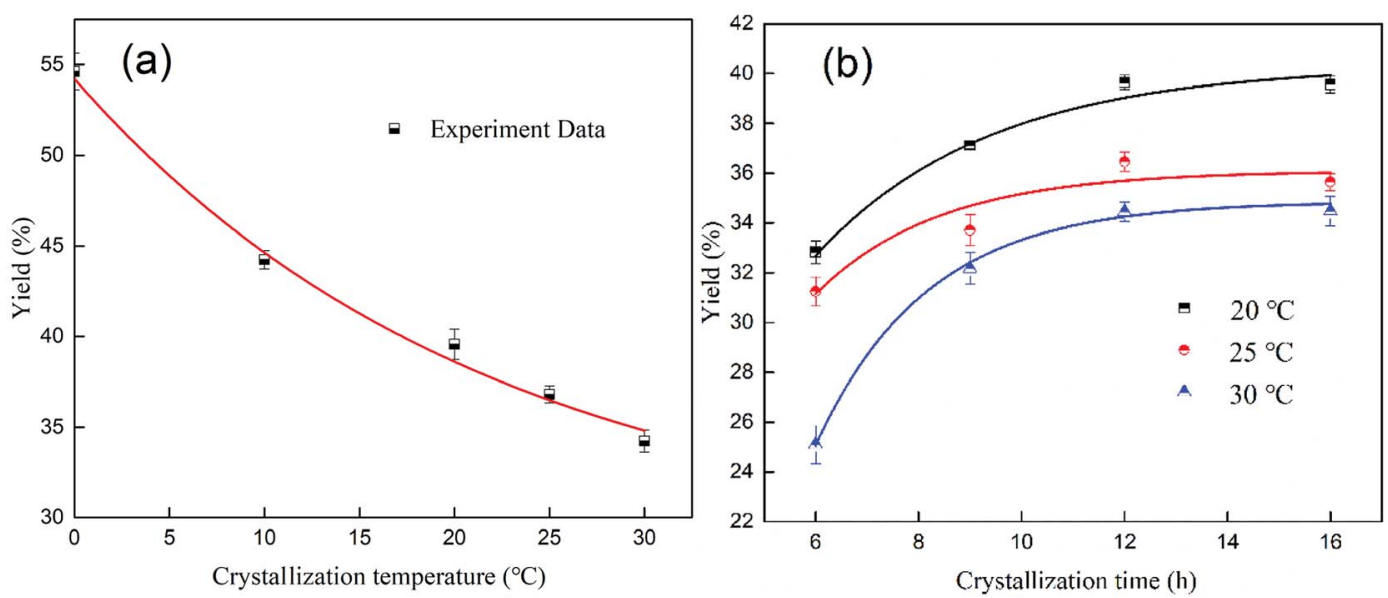

Fig. 2 Crystallization yield as a function of crystallization temperature (a) and time (b).
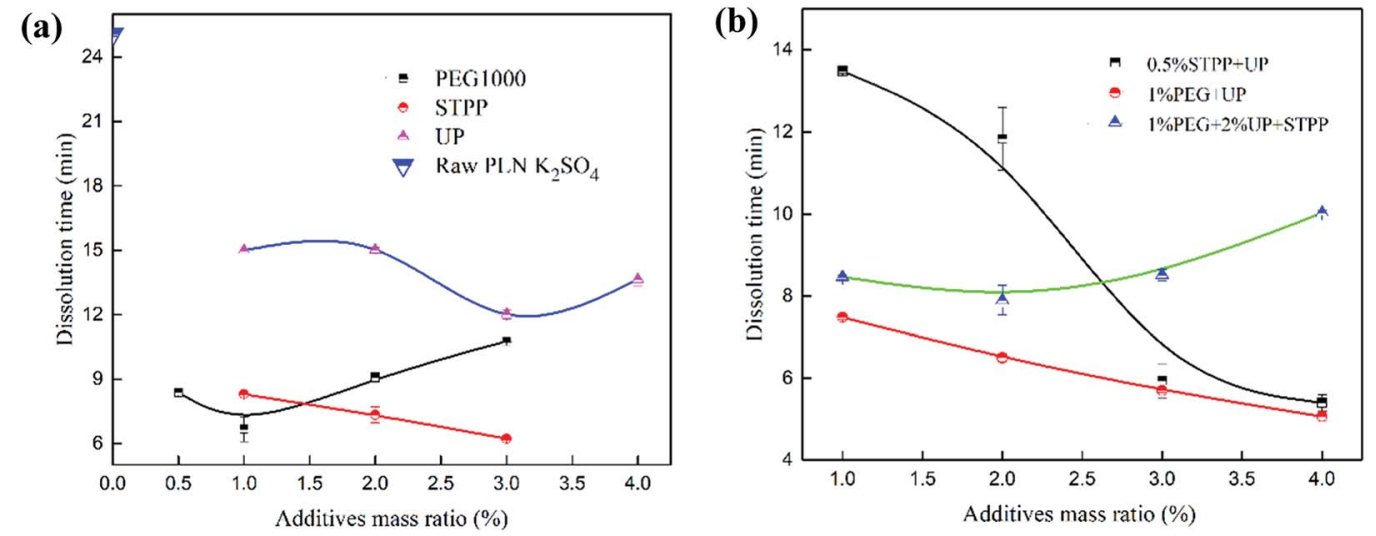

Fig. 3 Effect of a single additive (a) and mix additives (b) on the dissolution time.

\subsection{Rapid dissolution of potassium sulfate}

After the purification process, the purity of $\mathrm{K}_{2} \mathrm{SO}_{4}$ significantly improved. The rapid dissolution of $\mathrm{K}_{2} \mathrm{SO}_{4}$ was investigated in detail. Based on the Noyes-Whitney equation, the diffusion coefficient $(D)$ and diffusion layer thickness $(h)$, which were inherent properties of crystal $\mathrm{K}_{2} \mathrm{SO}_{4}$, were vital to the dissolution rate. ${ }^{18,25}$ Therefore, it is important to improve the $D$ and $h$ by changing $\mathrm{K}_{2} \mathrm{SO}_{4}$ crystal surface properties. Additives such as the dispersant and wetting agent could change the surface properties of $\mathrm{K}_{2} \mathrm{SO}_{4}$. These additives could improve the dispersity and wettability, resulting in an intrinsic change in the $D$ and $h .^{26}$

Fig. 3 shows the dissolution time after the $\mathrm{K}_{2} \mathrm{SO}_{4}$ crystal surface modification with some additives. It can be seen from Fig. 3(a) that addition of additives like PEG, STPP or UP promoted the dissolution of $\mathrm{K}_{2} \mathrm{SO}_{4}$ and decreased the dissolution time from $25 \mathrm{~min}$ to $6.25 \mathrm{~min}$ for PLN $\mathrm{K}_{2} \mathrm{SO}_{4}$. Fig. 3(b) describes the dissolution characteristics for $\mathrm{K}_{2} \mathrm{SO}_{4}$ with different mass ratios of mixing additives. Only the mass ratio of one additive was changed. Results demonstrated that the dissolution time was shorter by using mixture of additives rather than using a single additive. In addition, the dissolution time for the $0.5 \%$ STPP mass ratio and the $4 \%$ UP $(0.5 \%$ STPP/ $4 \%$ UP) with $1 \%$ PEG1000/4\% UP mass ratio was $5.5 \mathrm{~min}$ and 5 min, respectively. When the STPP mass ratio was higher than $0.5 \%$ UP, the mixture was difficult to dissolve and the solution became turbid. Moreover, PEG1000 was an expensive organic polymer that was difficult to decompose. In addition, PEG1000 is harmful to the environment and crops. UP and STPP have dispersity and can help to disperse $\mathrm{K}_{2} \mathrm{SO}_{4}$. Furthermore, UP contains nutrient elements such as $\mathrm{N}$ and $\mathrm{P}$, which can promote the growth of plants. Because STPP can be used for softening hard water, it can be applied to hard irrigation water. ${ }^{27}$ Moreover, STPP and UP are environment friendly. Therefore, after considering the price and performance of the additives, $0.5 \%$ STPP $/ 4 \%$ UP was chosen to be the combination additives.

The mechanism for promoting dissolution with additives is depicted in Fig. 4. It is well-known that STPP and UP are dispersants used to prepare suspensions. ${ }^{28,29}$ STPP and UP were attached to the surface of $\mathrm{K}_{2} \mathrm{SO}_{4}$ particles. When the samples were in water, the additives on the surface helped the $\mathrm{K}_{2} \mathrm{SO}_{4}$ particles to quickly disperse. This phenomenon resulted in an increase in the $D$ and an intrinsic decrease in the $h$. 


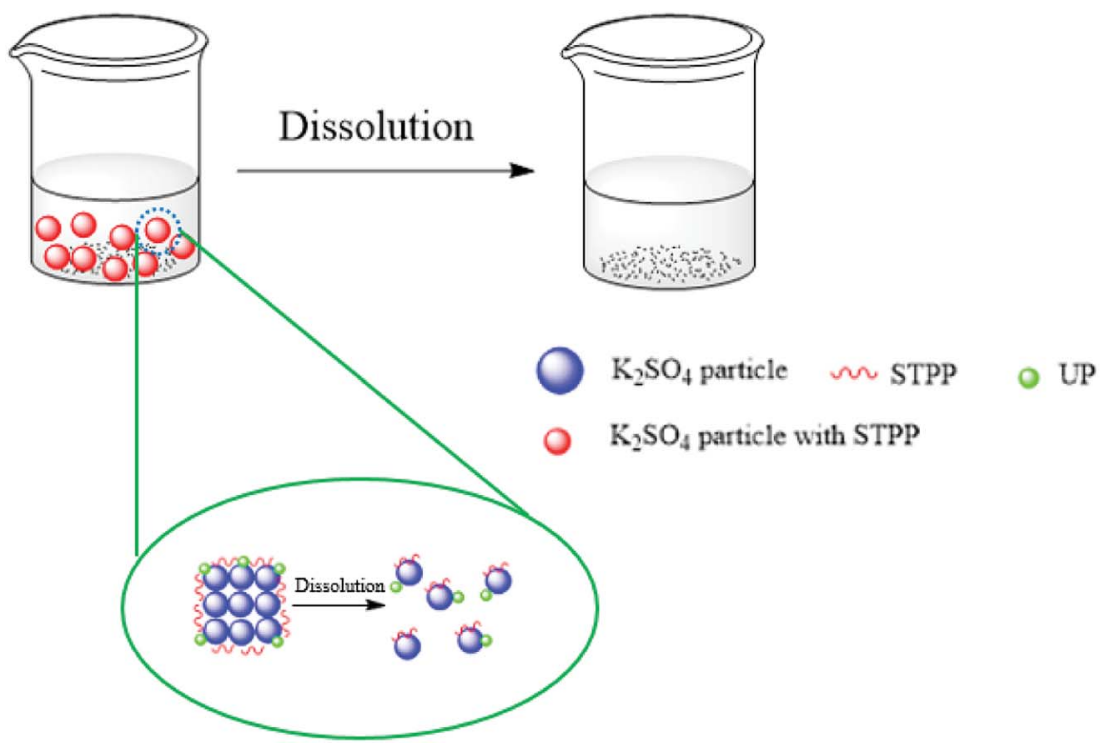

Fig. 4 Mechanism for $\mathrm{K}_{2} \mathrm{SO}_{4}$ particle dissolution with additives.

Table 5 Effect of crushing time on the particle size distribution

\begin{tabular}{lrrrr}
\hline \multicolumn{5}{c}{ Crushing time $(\mathrm{s})$} \\
\cline { 2 - 5 } Size fraction $(\mu \mathrm{m})$ & \multicolumn{1}{c}{5} & 10 & \multicolumn{1}{c}{20} & \multicolumn{1}{c}{40} \\
\hline+150 & 26.16 & 14.30 & 6.78 & 2.42 \\
$-150+74$ & 14.04 & 12.95 & 10.78 & 7.36 \\
-74 & 59.80 & 72.75 & 82.44 & 90.22 \\
Total & 100.00 & 100.00 & 100.00 & 100.00
\end{tabular}

The particle size was related to the surface area $(S) .{ }^{30-32}$ The particle size distribution for $\mathrm{PLN} \mathrm{K}_{2} \mathrm{SO}_{4}$ with $0.5 \%$ STPP/4\% UP varied with crushing time as shown in Table 5 . The effect of crushing time on the dissolution time is illustrated in Fig. 5. It can be concluded that the particle size had a significant influence on the dissolution time. As the particle size decreased, the

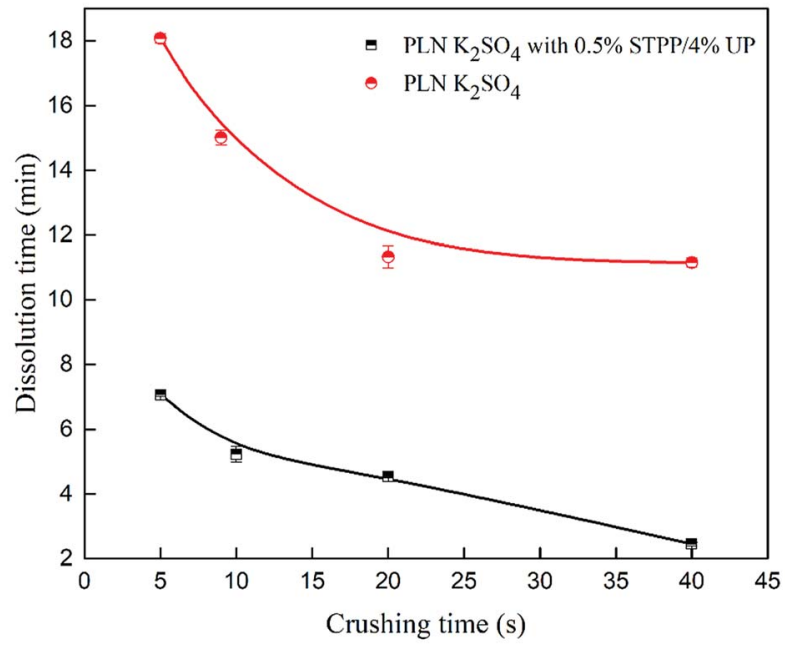

Fig. 5 Effect of particle size on the dissolution time. dissolution time for PLN $\mathrm{K}_{2} \mathrm{SO}_{4}$ and $\mathrm{PLN} \mathrm{K}_{2} \mathrm{SO}_{4}$ with $0.5 \% \mathrm{STPP} /$ $4 \%$ UP decreased. In addition, additives containing $0.5 \%$ STPP/ $4 \%$ UP had an extremely positive effect on the decrease in the dissolution time. As the particle size decreased, the surface area significantly increased, leading to an enhanced $S$. As a result, the dissolution rate was enhanced.

\section{Conclusion}

Water soluble potassium sulfate was successfully prepared from $\mathrm{LN} \mathrm{K}_{2} \mathrm{SO}_{4}$ as the raw material. The purity of $\mathrm{K}_{2} \mathrm{SO}_{4}$ was nearly $100 \%$ with a yield of $36.28 \%$ after the purification process. Additionally, the rapid dissolution process for $\mathrm{K}_{2} \mathrm{SO}_{4}$ was realized by the addition of a $0.5 \% \mathrm{STPP} / 4 \%$ UP additives, which modified the surface properties of the $\mathrm{K}_{2} \mathrm{SO}_{4}$ particle. This modification resulted in a larger diffusion coefficient $(D)$ and a smaller diffusion layer thickness $(h)$ during the dissolution process. Results also demonstrated that a larger $\mathrm{K}_{2} \mathrm{SO}_{4}$ surface area $(S)$ improved the dissolution rate.

\section{Conflicts of interest}

There are no conflicts of interest to declare.

\section{Nomenclature}

$\begin{array}{ll}\mathrm{d} m / \mathrm{d} t & \text { Dissolution rate, } \mathrm{kg} \mathrm{s}^{-1} \\ S & \text { Surface area, } \mathrm{m}^{2} \\ M & \text { Relative molecular mass, } \mathrm{g} \mathrm{mol}^{-1} \\ h & \text { Diffusion layer thickness, } \mathrm{m} \\ D & \text { Diffusion coefficient, } \mathrm{m}^{2} \mathrm{~s}^{-1} \\ C & \text { Concentration, mol L } \\ m & \text { Mass, } \mathrm{kg} \\ t & \text { Time, } \mathrm{s} \\ T & \text { Temperature, }{ }^{\circ} \mathrm{C}\end{array}$




\section{Acknowledgements}

The financial support for this study from the Natural Science Foundation of Hubei Province of China (2016CFA013, 2018CFB468) and Wuhan Science and Technology Bureau (2016070204020156) are gratefully acknowledged.

\section{References}

1 I. I. Goncharik, V. V. Shevchuk, N. P. Krut'Ko, A. D. Smychnik and O. A. Kudina, Russ. J. Appl. Chem., 2014, 87, 1804-1809.

2 K. G. Cassman, T. A. Kerby, B. A. Roberts, D. C. Bryant and S. M. Brouder, Agron. J., 1989, 6, 870-876.

3 M. Simonsson, S. Andersson, Y. Andrist-Rangel, S. Hillier, L. Mattsson and I. Öborn, Geoderma, 2007, 140, 188-198.

4 J. Niu, W. Zhang, S. Ru, X. Chen, X. Kai, X. Zhang, M. Assaraf, P. Imas, H. Magen and F. Zhang, Field Crops Res., 2013, 140, 69-76.

5 G. Yaldiz, Pharmacogn. Mag., 2017, 13, 102-107.

6 S. Su, H. Ma, X. Chuan and B. Cai, Int. J. Miner. Process., 2016, 155, 130-135.

7 A. V. Litvinovich, O. Y. Pavolva, A. I. Maslova and D. V. Chernov, Eurasian Soil Sci., 2006, 39, 785-791.

8 K. Kirov, Bulg. Tyutyun, 1995, 40, 13-15.

9 G. I. Rumiantsev, T. M. Khodykina and V. I. Arkhangel'Skil̆, Gig. Sanit., 1985, 8, 14-18.

10 S. K. Behera and R. K. Panda, Agric. Water Manag., 2009, 96, 1532-1540.

11 S. Zhang, V. Sadras, X. Chen and F. Zhang, Field Crops Res., 2013, 151, 9-18.

12 C. L. Liu, P. C. Jiao, M. L. Wang and Y. Z. Chen, Miner. Deposits, 2007, 26, 322-329.

13 C. L. Liu, M. L. Wang and P. C. Jiao, Acta Geosci. Sin., 2009, 30, 796-802.

14 M. Zheng, Y. Zhang, X. Liu, Q. I. Wen, F. Kong, N. Zhen and P. U. Linzhong, Acta Geosci. Sin., 2016, 90, 1195-1235.
15 L. Hao, Acta Geosci. Sin., 2008, 29, 517-524.

16 Y. Hattori, Y. Haruna and M. Otsuka, Colloids Surf., B, 2013, 102, 227-231.

17 A. A. Noyes and W. R. Whitney, J. Am. Chem. Soc., 2002, 19, 930-934.

18 A. Anand and G. N. Patey, J. Phys. Chem. B, 2018, 122, 12131222.

19 A. Dokoumetzidis, V. Papadopoulou and P. Macheras, Pharm. Res., 2006, 23, 256-261.

20 A. Xiang and A. J. Mchugh, J. Membr. Sci., 2011, 366, 104-115.

21 N. Kubota, I. Uchiyama, K. Nakai, K. Shimizu and J. W. Mullin, Ind. Eng. Chem. Res., 1988, 27, 930-934.

22 N. Kubota, J. Fukazawa, H. Yashiro and J. W. Mullin, J. Cryst. Growth, 1995, 149, 113-119.

23 N. Kubota, Y. Fujisawa, M. Yokota and J. W. Mullin, J. Cryst. Growth, 1999, 197, 388-392.

24 X. Y. Ji, D. L. Chen, T. Wei, X. H. Lu, Y. R. Wang and J. Shi, Chem. Eng. Sci., 2001, 56, 7017-7024.

25 R. J. Seager, A. J. Acevedo, F. Spill and M. H. Zaman, Sci. Rep., 2018, 8, 7711.

26 O. A. Slyusar and V. M. Uvarov, Glass Ceram., 2014, 71, 140142.

27 C. A. Hodge and T. W. Motes, Fert. Res., 1994, 39, 59-69.

28 H. Tan, Y. Guo, B. Ma, J. Huang, B. Gu and F. Zou, KSCE J. Civ. Eng., 2018, 22, 2934-2941.

29 H. Tan, F. Zou, B. Ma, M. Liu, X. Li and S. Jian, Constr. Build. Mater., 2016, 126, 617-623.

$30 \mathrm{~S} . \mathrm{Wu}, \mathrm{B} . \mathrm{Yu}, \mathrm{Z}$. Wu, S. Fang, B. Shi and J. Yang, RSC Adv., 2018, 8, 8544-8551.

31 J. Yu, L. Sun, C. Berrueco, B. Fidalgo, N. Paterson and M. Millan, J. Anal. Appl. Pyrolysis, 2018, 130, 127-134.

32 M. Liu, M. Shabaninejad and P. Mostaghimi, J. Pet. Sci. Eng., 2018, 170, 130-138. 